\title{
ANALISIS TIPOGRAFI PADA SPANDUK PEMASARAN PERUMAHAN
}

\section{Nadya Nur Rahman, Rahayu Sri Utami, Agung Zainal Muttakin Raden}

\author{
Program Studi Desain Komunikasi Visual \\ Fakultas Bahasa dan Seni, Universitas Indraprasta \\ Jl. Nangka No. 58C Tanjung Barat, Jagakarsa, Jakarta Selatan \\ Ndyrahman1@gmail.com,rahyuoek@gmail.com,agung.zainalmr@gmail.com
}

\begin{abstract}
Abstrak
Spanduk merupakan bagian dari media iklan lini bawah. Efektifitas spanduk dipasang di jalan diharapkan mampu menjaring minat audience. Awalnya spanduk berbahan kain dengan kemudian informasi yang diberikan dituliskan dengan mengunakan cat sablon, teknik ini sering disebut dengan teknik cetak saring, atau gaya desainnya disebut dengan gaya vernakular. Seiring kemajuan teknologi dunia cetak spanduk tidak hanya berbahan kain bisa juga menggunakan bahan flexy tenik yang digunakan dengan mencetak langsung melalui mesin cetak berskala besar. Dalam mendesain sebuah spanduk harus memperhatikan elemenelemen penting salah satunya yaitu tipografi. Tipografi pada spanduk harus bisa mewakili konsep dan karakteristik dari apa yang ingin disampaikan. Dalam penelitian ini dianalisis spanduk pemasaran perumahan yang terdapat dijalur lalulintas kendaraan di Jakarta berdasarkan hirarki dan kontras serta prinsip pokok tipografi (readability, legibility, dan visibility).
\end{abstract}

Kata kunci: tipografi, spanduk, pemasaran, perumahan

\section{TYPOGRAPHY ANALYSIS ON BANNER HOUSING MARKETING}

\begin{abstract}
The banner is part of the below the line media. The effectiveness of banners installed on the road is expected to capture the interest of the audience. Originally banner made of cloth with later information provided written by using screen printing paint, this technique is often referred to as screen printing techniques, or design style called vernacular style. Along with the advancement of technology world of banner prints not only fabric can also use the material flexy tenik used by printing directly through large-scale printing press. Effective advertising media in marketing a product or service one of which is banners. A banner is a span of cloth whose contents are propaganda, slogan or news that needs to be known by the public. Banners at this time as a media campaign that is quite popular, because the price is quite cheap and the process is very fast. In designing a banner should pay attention to the important elements one of which is typography. Typography on banners should be able to represent the concepts and characteristics of what to say. In this study analyzed housing sales banners contained in vehicle traffic in Jakarta based on hierarchy and contrast and basic principles of typography (readability, legibility, and visibility).
\end{abstract}

Keywords : typography, banners, marketing, housing 


\section{PENDAHULUAN}

Promosi tak terpisahkan dari kegiatan marketing. Pemasaran sebuah produk barang atau jasa memberikan dampak yang baik pada terlaksananya penjualan. Promosi melalui iklan dilakukan untuk mempermudah proses penyampaian pesan penjualan pada khalayak. Iklan sebagai media pemasaran mulai menciptakan konsep kreatif yang efektif dan menggugah konsumen (Setiyono, 2004: 17). Salah satu media iklan yang efektif dan kreatif dalam memasarkan sebuah produk barang atau jasa yaitu memalui spanduk. Spanduk sebagai suatu media informasi, biasanya dibuat dengan menggunakan cat, sablon atau dengan mesin cetak offset.

Spanduk sebagai salah satu media iklan terdiri dari unsur gambar (ilustrasi dengan tangan atau foto) digabungkan dengan unsur tertulis (huruf-huruf, katakata, dan kalimat) yang dirangkai sedemikian rupa dengan tujuan untuk menarik atau memikat pembaca. Dalam periklanan, saling pengaruh antara katakata dan gambar selalu membuat suatu impresi karena alasan tersebut ilustrasi dan judul dalam iklan selalu di pelajari sebagai sesuatu yang saling berhubungan (Soewardikoen, 2015: 119).

Dalam mendesain sebuah spanduk harus memperhatikan elemen-elemen penting salah satunya yaitu tipografi. Tipografi pada spanduk harus bisa mewakili konsep dan karakteristik dari apa yang ingin disampaikan. Pemilihan tipografi yang tepat tidak hanya dapat memberikan gambaran pada target audiens mengenai isi pesan tersebut tetapi juga dapat menarik dan memancing rasa ingin tahu mereka untuk menggunakannya.

Agar sebuah spanduk dapat berfungsi secara efektif sesuai dengan sasarannya maka harus memperhatikan tataletak unsur-unsur pembentuk pesan secara hirarki dan kontras serta memenuhi prinsip tipografi yang meliputi readability, legibility, dan visibility.

\section{PEMBAHASAN}

Pemasaran merupakan sebuah proses kegiatan yang dilakukan oleh perusahaan maupun individu yang menawarkan produk atau jasa kepada konsumen dengan tujuan untuk membuat konsumen tertarik dan berminat dengan barang dan jasa yang ditawarkannya. Dunia pemasaran saat ini persaingannya semakin banyak dan berat terutama dalam menarik perhatian konsumen agar dapat membeli barang atau jasa yang ditawarkan. Oleh karena itu segala usaha di bidang pemasaran (Marketing) harus ditempuh dengan keras agar dapat bertahan dalam persaingan bisnis.

Pemasaran tak terpisahkan dari kegiatan promosi. Pemasaran sebuah produk barang atau jasa memberikan dampak yang baik pada terlaksananya penjualan. Untuk menghadapi persaingan bisnis dan mempermudah proses penyampaian pesan penjualan pada khalayak maka diperlukannya media promosi yang lebih menarik dan efektif yaitu melalui iklan media luar ruang spanduk (Banner). Iklan sebagai media pemasaran mulai menciptakan konsep kreatif yang efektif dan menggugah konsumen (Setiyono, 2004: 17). Menurut KBBI online, spanduk adalah suatu kain rentang yang isinya propaganda, slogan ataupun berita yang perlu diketahui oleh umum. spanduk yaitu kain membentang yang biasanya berada di tepi jalan yang berisi text, berwarna serta bergambar.

Spanduk sebagai suatu media informasi, biasanya dibuat dengan menggunakan cat, sablon (screen printing) atau dengan mesin cetak (offset). Spanduk berfungsi sebagai media promosi baik itu berupa produk atau jasa. Selain itu spanduk merupakan media promosi yang 
murah dan sangat efektif. Dengan melihat spanduk yang menarik, konsumen pun akan tertarik untuk membeli produk atau jasa yang ditawarkan.

Spanduk sebagai salah satu media iklan terdiri dari unsur gambar (ilustrasi dengan tangan atau foto) digabungkan dengan unsur tertulis (huruf-huruf, katakata, dan kalimat) yang dirangkai sedemikian rupa dengan tujuan untuk menarik atau memikat pembaca. Dalam periklanan, saling pengaruh antara katakata dan gambar selalu membuat suatu impresi karena alasan tersebut ilustrasi dan judul dalam iklan selalu di pelajari sebagai sesuatu yang saling berhubungan (Soewardikoen, 2015: 119).

Spanduk sebagai media iklan yang efektif ditandai dengan adanya sinergi di antara unsur judul, nas (body text) dan ilustrasi. Kedua unsur tersebut bekerjasama untuk menarik perhatian pemirsa membuat pengamat bersuasana hati mau menerima ide-ide baru yang disampaikan iklan. Hal yang membuat tata-letak iklan pada spanduk dianggap tersusun yaitu hirarki dan kontras serta memenuhi prinsip tipografi yang meliputi readability, legibility, dan visibility.

Tipografi adalah sarana bentuk visualisasi pada ide yang tertulis. Tipografi merupakan salah satu elemen yang paling penting untuk membentuk karakter dan atribut yang dapat mempengaruhi emosional pada sebuah desain.

Perlunya memperhatikan prinsip tipografi dalam menggunakan huruf sebagai unsur-unsur pendukung, karena huruf yang dilihat memiliki energi untuk memberikan kekuatan dalam membangkitkan gerak mata. Agar energi yang dikeluarkan memberikan efek positif. Ergonomi tipografi adalah sebaran huruf yang dirancang demi kenyamanan membaca tanpa memberikan efek kelelahan pada mata.
Berdasarkan pembahasan diatas penelitian ini menganalisis tipografi pada spanduk pemasaran perumahan di Jakarta, apakah sudah dianggap tersusun berdasarkan hirarki, kontras dan memenuhi prinsip tipografi.

\section{Analisis Tipografi pada Spanduk Pemasaran Perumahan}

Tipografi yang digunakan pada desain spanduk perumahan ini biasanya dibuat secara digital, tipografi tersebut menginformasikan tentang harga promo yang tersedia pada perumahan yang siap huni, seperti cicilan, bunga, dan fasilitas yang dihadirkan oleh perumahan tersebut.

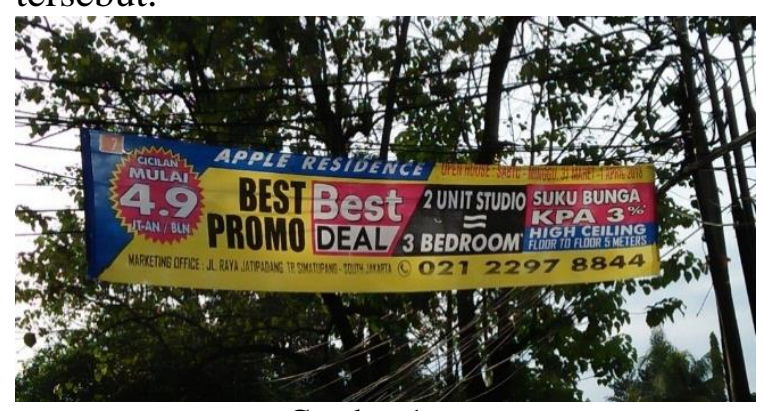

Gambar 1.

Spanduk Perumahan Jati Padang (Sumber: Utami, 2018)

Pada Gambar 1 Sequence informasi yang ditampilkan diawali dengan penekanan pada teks Best Promo, warnanya hitam dan ukuran typeface lebih besar dari ukuran typeface lainnya. Huruf yang digunakan berjenis bold sans serif atau huruf berjenis sans serif tebal dengan latar belakang berwarna kuning menampilkan tipografi terlihat kontras dan mudah dibaca. Pembuatan spanduk ini dengan menggunakan teknik digital.

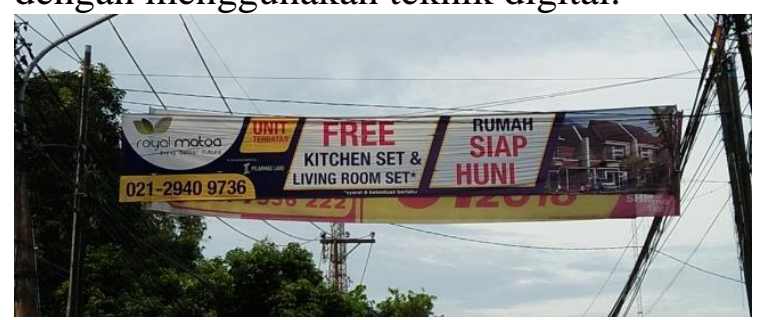

Gambar 2.

Spanduk Perumahan Royal Matoa (Sumber: Utami, 2018) 
Pada Gambar 2 sequence informasi yang menjadi pusat perhatian adalah tulisan Rumah Siap Huni, dan Free dengan ukuran typeface lebih besar dari huruf yang lain, menggunakan klasifikasi huruf sans serif. Huruf diberi warna merah dengan menggunakan latar belakang spanduk yang berwarna putih. Artworks yang digunakan gambar rumah di sebelah kanan, dan terdapat identitas Royal Matoa pada sebelah kiri dengan latar belang berwarna putih dan tipografi menggunakan warna hitam. Dari gambargambar tersebut kita dapat melihat hirarki dan kontras pada susunan hurufhurufnya.

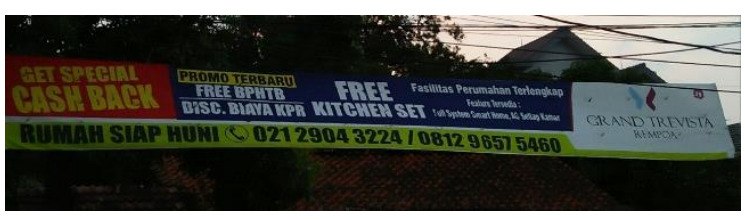

Gambar 3.

Spanduk Perumahan Grand Trevisia

(Sumber: Utami, 2018)

Pada Gambar 3 sequence informasi yang pusatkan adalah Get Special Cash Back, dengan ukuran typeface lebih besar dari huruf yang lain. Huruf yang digunakan adalah Sans Serif. Huruf yang digunakan berwarna kuning dengan posisi diagonal dengan latar belakang warna merah. Dari gambar-gambar tersebut kita dapat melihat hirarki dan kontras pada susunan huruf-hurufnya.

\section{Hirarki dan Kontras}

Hirarki huruf pada spanduk perumahan dapat diartikan sebagai arah atau alur baca serta sebagai pembeda antara header dan body text. Bentuk yang berbeda dapat menggunakan jenis huruf yang sama hanya ukuran lebar dan tinggi huruf diperkecil, atau gaya huruf yang berbeda, atau dengan memberikan warna yang berbeda pada setiap informasi yang ditampilkan pada spanduk tersebut. Hirarki dalam tipografi berfungsi sebagai pemberi kesan layout yang bersih, tidak ambigu dan mudah untuk diarahkan. Hirarki dapat berbentuk ukuran berat font yang berbeda, ukuran point serta gaya dan klasifikasi. Menurut Ambrose \& Harris, 2009: 82 dikatakan bahwa sebuah hirarki yang sederhana dapat diciptakan dengan memberikan warna yang berbeda pada huruf yang sama.

Kontras merupakan unsur yang penting untuk mendukung kualitas baca dari informasi yang ditampilkan. Rangkaian huruf-huruf tersebut mudah untuk dibaca dan dikenali. Kontras merupakan unsur terpenting dalam memberikan kesan sebuah kata, kalimat atau paragraf mudah tidaknya untuk dibaca. Menurut Cronin (dalam Akbar dan Raden, 2016:179) dikatakan bahwa kontras yang baik menjadikan sebuah kata, kalimat atau sebuah paragraf mudah untuk dibaca dan memudahkan mata dalam mengenali huruf-huruf tersebut.

Pada Gambar 4 yang menjadi header adalah Best Promo menggunakan huruf Sans Serif, dengan ukuran huruf besar, diberi Bold warna hitam. Spesifikasi detail disampingnya menggunakan huruf Sans Serif dengan ukuran lebih kecil dari header. Kemudian di bagian atas terdapat identitas Apple Residence dengan klasifikasi huruf Sans Serif Italic. Pada bagian bawah terdapat closing yang menggunakan huruf Sans Serif. Latar belakang kain dominan berwarna kuning dengan penekanan Best Promo, warna biru, warna merah dan hitam. Penggunaan warna-warna primer membuatnya menjadi titik pusat perhatian diantara spanduk lainnya. Warna pada huruf menggunakan warna putih, hitam, dan merah.

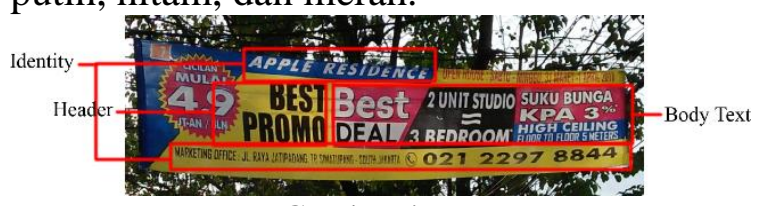

Gambar 4.

Kontras dan Hirarki

(Sumber: Utami, 2018) 
Pada Gambar 5 yang menjadi header adalah Rumah Siap Huni menggunakan huruf Sans Serif dan warna merah pada Siap Huni membuat mata langsung tertuju pada header. Kemudian identitas Royal Matoa dengan huruf Sans Serif. Body text menggunakan Sans Serif. Dibagian bawah kiri terdapat closing menggunakan huruf Sans Serif. Latar spanduk berwarna putih, biru serta kuning. Warna pada huruf biru dan merah.

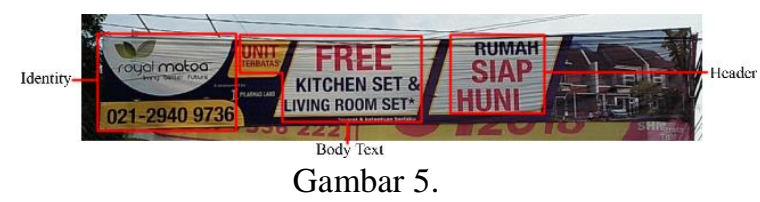

Kontras dan Hirarki

(Sumber: Utami, 2018)

Pada Gambar 6 yang menjadi header adalah Get Special Cash Back, menggunakan huruf sans serif, dengan ukuran huruf yang besar, diberi warna kuning dan background berwarna merah menunjukan efek kontras pada spanduk tersebut. Mengenai informasi yang disampaikan pada tulisan yang berada disamping kanan Get Special Cash Back yang di cetak miring pada cash back nya, menggunakan huruf sans serif dengan ukuran yang lebih kecil tanpa shadow, kemudian di sebelah kanan tulisan terdapat identitas dari spanduk itu yaitu Grand Trevisia, yang menjadi identitas dari rumah siap huni tersebut. Ukuran huruf lebih kecil dari header dengan klasifikasi huruf yang digunakan adalah sans serif, dengan latar spanduk berwarna putih, biru tua, merah dan kuning. Adapun terdapat berbagai macam warna pada tulisan spanduk tersebut, seperti tulisan berwarna kuning pada cash back menjadi daya tarik bagi orang yang melihatnya. Warna putih pada informasi mengenai perumahan tersebut, dan warna hitam pada nomor telepon perumahan.

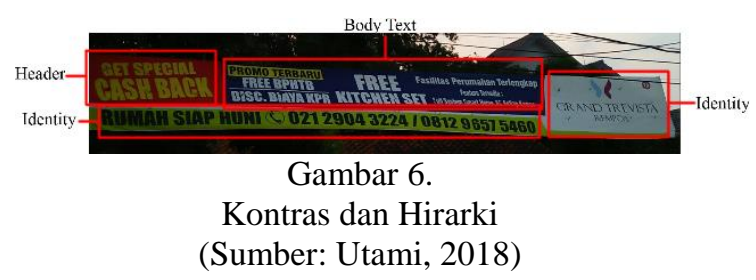

\section{Prinsip Tipografi}

Prinsip tipografi yang digunakan untuk menganalisis tipografi ini adalah legability, readability, visibility dan clarity. Legability memiliki pengertian sebagai kualitas hurus dalam tingkat kemudahannya untuk dikenali atau dibaca. Readability lebih kepada kualitas kemudahan dan kenyamanan dibacanya rangkaian huruf dalam sebuah desain tipografi atau tata letak layout (Sihombing, 2015: 165). Menurut Ekawardhani dan Natagracia (dalam Akbar dan Raden, 2016: 180) Visibility merupakan sebuah kemampuan huruf dan teks yang untuk dapat dimengerti dengan jelas (, 2017: 87).

Prinsip tipogafi yang akan dianalisis adalah header dan identity pada gambar-gambar di bawah ini.

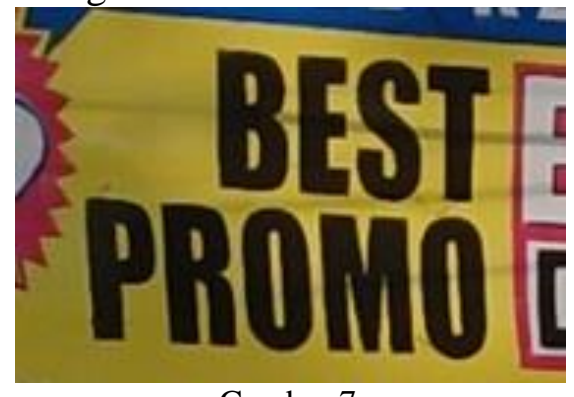

Gambar 7.

Prinsip Tipografi pada Header 1 (Sumber: Utami, 2018)

\section{Header 1}

1. Klasifikasi huruf dan warna Klasifikasi huruf sans serif dengan warna hitam.

2. Legibility

Tipogafi pada header tersebut dapat terbaca. Warna hitam pada typefaces yang terdapat pada header dengan warna latar belakang yang berwarna kuning sangat kontras, dapat mempengaruhi legibility atau tingkat 
keterbacaan dari header. Header mudah dibaca.

3. Readability

Ruang yang terdapat pada susun-an huruf yang terdapat dalam header tidak terlalu rapat dan tidak terlalu renggang. Pemilihan huruf sans serif sangatlah tepat mengingat adanya pemberian warna hitam dengan latar belakang kuning memberikan pesan yang menonjol.

4. Visibility

Penggunaan warna pada typefaces kontras dengan latar belakang berwana kuning, maka jarak pandang normal.

5. Clarity

Typefaces berwarna hitam memberikan kesan kuat, kokoh sehingga memberikan clarity yang baik.

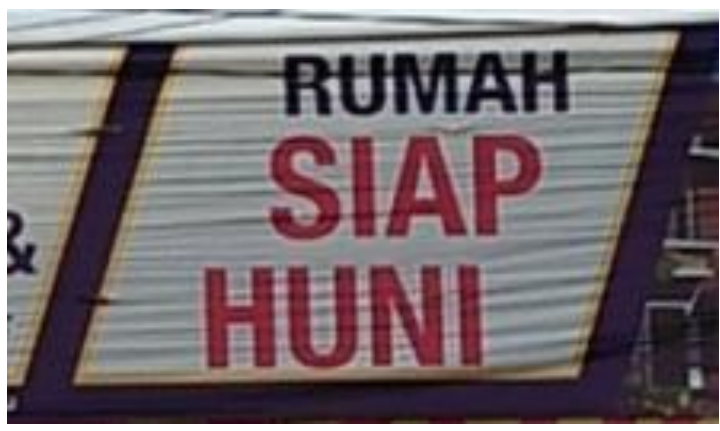

Gambar 8.

Prinsip Tipografi pada Header 2

(Sumber: Utami, 2018)

\section{Header 2}

1. Klasifikasi huruf dan warna

Klasifikasi huruf sans serif. Rumah berwarna biru dan Siap Huni berwarna merah.

2. Legibility

Tipogafi pada header tersebut dapat terbaca. Warna biru pada typefaces Rumah dan warna merah pada typefaces Siap Huni yang terdapat pada header dengan latar belakang yang berwarna putih dengan border warna kuning sangat kontras, dapat mem-pengaruhi legibility atau tingkat keterbacaan dari header. Tingkat keterbacaan pada header lebih tertuju pada Siap Huni. Secara keseluruhan Header mudah dibaca.

\section{Readability}

Ruang yang terdapat pada susunan huruf dalam header terlihat sedikit rapat karna masih banyaknya ruang kosong pada latar belakang.

4. Visibility

Penggunaan warna pada typefaces kontras dengan latar belakang berwana putih, maka jarak pandang normal.

5. Clarity

Typefaces berwarna biru dan merah memberikan kesan berani, sehingga memberikan clarity yang baik.

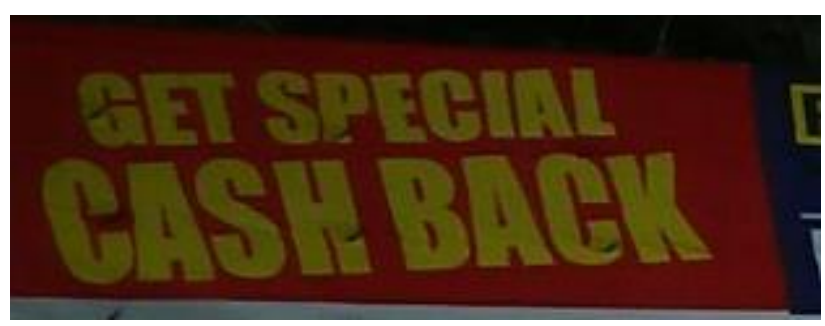

Gambar 9.

Prinsip Tipografi pada Header 3 (Sumber: Utami, 2018)

\section{Header 3}

1. Klasifikasi huruf dan warna Klasifikasi huruf sans serif dengan warna kuning.

2. Legibility

Tipografi pada header tersebut dapat terbaca. Warna typeface kuning dengan latar belakang yang berwarna merah sangat kontras, dapat mempengaruhi legibility atau tingkat keterbacaan dari header. Header mudah dibaca.

3. Readability

Ruang yang terdapat pada susunan huruf dalam header terlihat agak rapat karena jenis typefacesnya yang terlalu tebal dan penempatan posisinya yang diagonal membuat ruang susunan huruf terlihat sempit. 


\section{Visibility}

Penggunaan warna pada typefaces kontras dengan latar belakang berwana merah, maka jarak pandang normal.

5. Clarity

Typefaces berwarna kuning memberikan kesan berani, sehingga memberikan clarity yang baik.

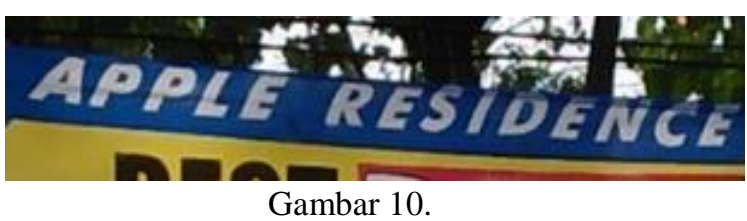

Prinsip Tipografi pada Identity 1

(Sumber: Utami, 2018)

\section{Identity 1}

1. Klasifikasi huruf dan warna

Klasifikasi huruf yang digunakan sans serif dengan warna huruf putih.

2. Legibility

Tipografi pada identity tersebut dapat terbaca. Warna putih pada typefaces yang terdapat pada identity dengan warna latar belakang berwarna biru sangat kontras, dapat mempengaruhi legibility atau tingkat keterbacaan dari identity.

3. Readability

Ruang yang terdapat pada susunan huruf yang terdapat dalam identity terlihat tidak terlalu rapat. Pemilihan huruf dengan klasifikasi sans serif dan menggunakan upper case memberi kesan kokoh dan kuat.

4. Visibility

Penggunaan warna pada typefaces kontras dengan latar belakang berwarna biru, maka dengan jarak pandang normal 6 meter, identity masih dapat dibaca dengan baik.

5. Clarity

Penggunaan typefaces sans serif sangat kuat, untuk memberikan kesan kuat, kokoh dan tegas memberikan clarity yang baik.

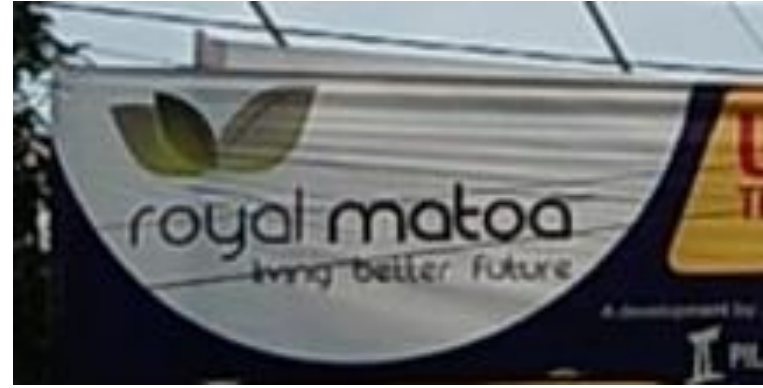

Gambar 11.

Prinsip Tipografi pada Identity 2

(Sumber: Utami, 2018)

Identity 2

1. Klasifikasi huruf dan warna Klasifikasi huruf yang digunakan sans serif dengan warna biru gelap.

2. Legibility

Tipografi pada identity tersebut dapat terbaca. Warna biru gelap pada typefaces yang terdapat pada identity dengan warna latar belakang berwarna putih sangat kontras, dapat mempengaruhi legibility atau tingkat keterbacaan dari identity.

3. Readability

Penggunaan warna pada typefaces kontras dengan latar belakang berwarna putih, maka dengan jarak pandang normal 6 meter, identity masih dapat dibaca dengan baik.

4. Visibility

Penggunaan warna pada typefaces kontras dengan latar belakang berwarna putih, maka dengan jarak pandang normal 6 meter, identity masih dapat dibaca dengan baik.

5. Clarity

Penggunaan typefaces sans serif sangat kuat, untuk memberikan kesan kuat, kokoh dan tegas memberikan clarity yang baik. 


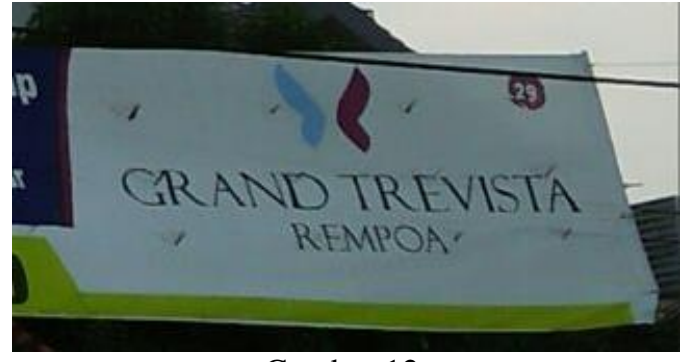

Gambar 12.

Prinsip Tipografi pada Identity 3

(Sumber: Utami, 2018)

\section{Identity 3}

1. Klasifikasi huruf dan warna

Klasifikasi huruf yang digunakan sans serif dengan warna ungu gelap.

2. Legibility

Tipografi pada identity tersebut dapat terbaca. Warna ungu gelap pada typefaces yang terdapat pada identity dengan warna latar belakang berwarna putih sangat kontras, dapat mempengaruhi legibility atau tingkat keterbacaan dari identity.

3. Readability

Penggunaan warna pada typefaces kontras dengan latar belakang berwarna putih, maka dengan jarak pandang normal 6 meter, identity masih dapat dibaca dengan baik.

4. Visibility

Penggunaan warna pada typefaces kontras dengan latar belakang berwarna putih, maka dengan jarak pandang normal 6 meter, identity masih dapat dibaca dengan baik.

5. Clarity

Penggunaan typefaces sans serif sangat kuat, untuk memberikan kesan kuat, kokoh dan tegas memberikan clarity yang baik.

\section{SIMPULAN}

Tipografi yang digunakan pada spanduk pemasaran perumahan kebanyakan menggunakan jenis huruf sans serif pada body text dan serif digunakan pada identity. Pemilihan warna pada latar belakang menggunakan warna yang cerah untuk menimbulkan kesan kontras pada bagian header sebagai pusat perhatian utama. Prinsip tipografi pada spanduk pemasaran perumahan telah diterapkan berdasarkan hasil analisis yang telah dilakukan, meliputi readability, legibility, dan visibility, serta hirarki dan kontras. Oleh karena itu, pentingnya untuk mengetahui jenis tipografi , pemilihan warna pada tipografi dan latar belakang spanduk, dan prinsipprinsip tipografi agar dapat dilihat sesuai dengan jarak pandang dan dapat mempengaruhi konsumen untuk mengambil keputusan dalam apa yang ditawarkan yang terdapat pada spanduk.

Spanduk sebagai media iklan promosi yang efektif dan kreatif dapat mempermudah proses pemasaran produk atau jasa, memberikan dampak yang baik pada terlaksananya penjualan yaitu untuk menghadapi persaingan bisnis dan mempermudah proses penyampaian pesan penjualan pada khalayak.

\section{DAFTAR PUSTAKA}

Akbar, T., \& Raden, A. Z. (2016). Tipografi Vernakular Pada Warung Tenda Kaki Lima Jakarta. Dimensi DKV Seni Rupa dan Desain, 175-183.

Ambrosse, G., \& Harris, P. (2009). The Fundamental of Graphic Design. Swizterland: AVA Publishing SA.

Setiyono, B. (2004). Reka Reklame. Jakarta: Galang Press.

Sihombing, D. (2015). Tipografi Dalam Desain Grafis. Jakarta: PT. Gramedia Pustaka Utama.

Soewardikoen, D. W. (2015). Visualisasi Iklan Indonesia era 1950-1957. Yogyakarta: CALPULIS. 